\title{
On a novel strategy for water recovery and recirculation in biorefineries through application of forward osmosis membranes
}

Kalafatakis, Stavros; Braekevelt, Sylvie; Carlsen, Vilhelmsen; Lange, Lene; Skiadas, loannis V.; Gavala, Hariklia N.

\section{Published in:}

Chemical Engineering Journal

Link to article, DOI:

10.1016/j.cej.2016.11.092

Publication date:

2017

Document Version

Peer reviewed version

Link back to DTU Orbit

Citation (APA):

Kalafatakis, S., Braekevelt, S., Carlsen, V., Lange, L., Skiadas, I. V., \& Gavala, H. N. (2017). On a novel strategy for water recovery and recirculation in biorefineries through application of forward osmosis membranes.

Chemical Engineering Journal, 311, 209-216. https://doi.org/10.1016/j.cej.2016.11.092

\section{General rights}

Copyright and moral rights for the publications made accessible in the public portal are retained by the authors and/or other copyright owners and it is a condition of accessing publications that users recognise and abide by the legal requirements associated with these rights.

- Users may download and print one copy of any publication from the public portal for the purpose of private study or research.

- You may not further distribute the material or use it for any profit-making activity or commercial gain

- You may freely distribute the URL identifying the publication in the public portal 


\title{
On a novel strategy for water recovery and recirculation in biorefineries through application of forward osmosis membranes
}

Stavros Kalafatakis ${ }^{\mathrm{a}}$, Sylvie Braekevelt ${ }^{\mathrm{b}}$, Niels S. Vilhelmsen Carlsen ${ }^{\mathrm{a}}$, Lene Lange ${ }^{\mathrm{a}}$, Ioannis V.

Skiadas $^{\mathrm{a}}$, Hariklia N. Gavala ${ }^{\mathrm{a}^{*}}$

${ }^{\mathrm{a}}$ Technical University of Denmark (DTU), Department of Chemical and Biochemical Engineering, Søltofts Plads 229, 2800 Kgs. Lyngby, Denmark.

${ }^{\mathrm{b}}$ Aquaporin A/S, Nymøllevej 78, 2800 Kgs. Lyngby, Denmark

${ }^{*}$ Corresponding author: e-mail: hnga@kt.dtu.dk \& hari_gavala@yahoo.com tel: +4545256196

\begin{abstract}
A great amount of research has been performed during the last 10 years focusing on forward osmosis (FO) processes. The main driving force is to find an effective and low energy demanding methodology for water recovery as well as up-concentration of valuable products. Nevertheless, the energetic and financial benefits of this technology can be undermined from the fact that FO should be usually coupled with reverse osmosis (RO) for subsequent water purification and draw solution regeneration. Hence, a different approach was applied in order to omit the RO step. Crude glycerol and enzymatically pretreated wheat straw, which are common $2^{\text {nd }}$ generation biorefinery feedstocks, have been evaluated as possible draw solution. In this way, water can be directly recovered and transferred back into the fermentation loop without further purification. Applying the Aquaporin Inside $^{\mathrm{TM}}$ Forward Osmosis system, crude glycerol and wheat straw hydrolysate have demonstrated
\end{abstract}


water fluxes up to $10.5 \mathrm{~L} / \mathrm{m}^{2} / \mathrm{h}$ and $5.37 \mathrm{~L} / \mathrm{m}^{2} / \mathrm{h}$, respectively. Furthermore, economic analysis of FO coupled with bioprocessing has demonstrated that substantial financial cost reduction regarding the product recovery can be achieved. All in all, this novel approach can be applied for both water recovery and up-concentration of soluble products in the fermentation broth and presents a great potential within biorefineries.

Keywords: Forward osmosis; downstream processing; biorefineries, fermentation; water re-use; technoeconomic analysis

\section{Introduction}

Anthropogenic influence on global climate change is one of the greatest challenges in the modern society with greenhouse gases $(\mathrm{GHG})$ emission reaching a record high. According to the Intergovernmental Panel for Climate Change (IPCC) the effects on climate change will continue for many years even if the GHG emission is reduced considerably [1]. Hence the necessity for a transition to alternative and more sustainable resources is deemed necessary. Among others, bioconversion of non-food and waste biomasses to food and feed ingredients, bio-based chemicals, biomaterials and biofuels but also the production of renewable based fertilisers has attracted large attention. The valorisation of lignocellulosic, domestic and industrial residues and the relevant technological advances are investigated in the frame of $2^{\text {nd }}$ generation biorefineries $[2,3]$.

However, industrial application of bioconversions for production of fuels and bulk chemicals from lignocellulosic biomasses and industrial effluents is still limited mainly due to the higher production cost when compared to crude oil-based alternatives. A common bottleneck for the cost effectiveness of most bioprocesses is the relatively low concentration of the targeted product at the effluent stream, which results in increased downstream processing cost. However, increasing the titer of the final product is not always feasible due to various inhibition effects. Common sources of 
inhibition are i) the feedstock chemical composition, ii) the substrate itself, iii) the product or, in most cases iv) a combination of the above. For example, sugars bound in lignocellulosic biomass are not readily available for bioconversion and thus a pretreatment step is most often than not a necessity [4]. However various inhibitors for the subsequent biological step can be released during pre-treatment, i.e. aliphatic acids, furfurals and phenolic compounds [4]. Another promising feedstock for valorization in the frame of $2^{\text {nd }}$ generation biorefineries is crude glycerol generated during biodiesel production [5]. Crude glycerol represents $10 \%$ of the total production volume and due to the great amounts generated nowadays, is considered as a waste product and its disposal can become rather costly process [6]. Glycerol can be biologically converted into various products i.e. butanol, 1,3 propanediol and ethanol [5,7]. However, like in the case of pretreated lignocellulosic feedstocks, impurities like long chain fatty acids, soaps, methanol and salts inhibit the bioconversion of crude glycerol [8]. Last but not least, end-product inhibition is very common in anaerobic fermentations, among others in ethanol and butanol fermentations but also in butyric acid fermentations $[5,9,10]$. Numerous studies have focused on overcoming inhibition effects and various methods have been suggested and developed. Among them, microbial selection/adaptation, genetic engineering and medium detoxification have been proposed when lignocellulosic biomasses are concerned $[4,11,12]$, while crude glycerol can be purified by mechanical, chemical and biological treatments [13]. In situ removal of inhibitory end-products is an effective way to overcome product inhibition and it has so far been applied on bench-scale acids and alcohols fermentations $[14,15]$.

Recovery and reuse of water from the effluent of the biological step in a non-energy intensive manner, could potentially improve the economy of bioconversion processes. In this regard, Forward Osmosis (FO) separation technology has the potential of being applied to biorefineries for water reuse from the dilute effluents. FO technology uses semipermeable membranes, designed to ensure 
high water flux, rejection of small solutes and long-term chemical and mechanical stability [16]. The mode of operation includes the transfer of water from a low osmotic pressure solution (feed solution, FS), through the membrane, to a high osmotic pressure solution (draw solution, DS) [16]. FO functions either as a stand-alone technology, if the diluted draw solution can be used directly (direct FO) or together with an auxiliary separation technology, when clean water is the product (indirect FO) [17]. For commercialization of the FO technology, recent studies have identified draw solution regeneration and membrane development as the key challenges [16]. Hence, many complex draw solutions have been tested and established the last decade like nanoparticles, hydrogels and various solvents $[18,19]$.

Nowadays, industrial applications of FO technology are within the seawater/brackish water desalination, wastewater treatment and food processing fields [20]. For production of clean water and regeneration of the draw solution, FO is usually combined with Reverse Osmosis (RO) membranes, since bivalent and monovalent inorganic salts are the most frequently used draw solutes $[16,19]$. More often than not, FO technology is regarded as an "advanced pre-treatment technology" for liquid effluents that are not suitable for direct application of RO or other membrane separations as FO is less sensitive to suspended constituents, dissolved organic material and inorganic scalants [19]. In short, the status of FO technology nowadays is well-described by Shaffer et al. as "FO process is not intended to replace RO but rather is to be used to process feed water that cannot be treated by RO". Therefore, the overall economy and energy requirements of a combined FO/draw solution regeneration are not improved when compared to RO alone although FO technology is not an energy intensive process per se and it also carries the additional advantage of the highly reversible fouling [19].

Hereby, we propose an alternative approach regarding the FO membrane separation and the use of feed and draw solutions. As discussed above, the regeneration of the DS increases the energy 
requirements and expenditures of water recovery. Hence we suggest the use concentrated feedstock directly as DS while the effluent of the biological process can serve as FS. This way no drawsolution re-generation is required and therefore only FO with low energy requirements will be applied (Fig. 1).Make-up water is fed to the influent stream to obtain the desired feedstock concentration depending on the achievable recovery of this water re-use system.

The present manuscripts focuses on two preliminary questions that emerge for such an approach: a) whether the obtained water flux is high enough to justify application of FO technology and b) to what extent the downstream processing economics are improved by the application of low energy water recovery. Regarding the first topic, two commonly $2^{\text {nd }}$ generation biorefinery feedstocks, wheat straw hydrolysate and crude glycerol, have been tested for their water recovery potential by applying the Aquaporin Inside ${ }^{\mathrm{TM}}$ Forward Osmosis system. This biomimetic membrane system is based on using protein as water channels [21] and as reviewed by Habel et al. [22] aquaporin based membranes are imitating the biological processes of living cells and are potentially advantageous compared to conventional membranes regarding water specificity, water flux and solutes rejection. In order to focus on the potential of real feedstocks to be used as draw solutions and eliminate other factors affecting the water fluxes, e.g. microbial cells leading to biofouling, diluted feedstocks instead of fermentation effluents were initially used as feed solutions. Finally, the second question was addressed by applying a techno economic evaluation of the downstream processing cost for the most promising feedstock and process, namely fermentative butanol production from crude glycerol, with and without FO application. 


\section{Materials and methods}

\subsection{Feedstocks}

Pretreated and enzymatically Hydrolysed Wheat Straw (PHWS) was provided by BioGasol®, Denmark. The pretreatment and enzymatic hydrolysis was done as described in Baroi et al. [12]. The composition of PHWS per litre of solution was: $72 \mathrm{~g}$ glucose, $55 \mathrm{~g}$ xylose, $4.2 \mathrm{~g}$ arabinose, 2.3 cellobiose, $7.1 \mathrm{~g}$ acetate, $0.02 \mathrm{~g}$ 5-HMF, 0.18g 2-Furfural, $0.2 \mathrm{~g}$ inorganic nitrogen (measured as $\mathrm{NH}_{3}-\mathrm{N}$ ) and $0.11 \mathrm{~g}$ inorganic phosphorus (measured as $\mathrm{PO}_{4}-\mathrm{P}$ ) [12]. The PHWS was subjected to filtration through an $8 \mu \mathrm{m}$ pore size filter prior to use.

Crude Glycerol (CG) was provided by Daka ecoMotion, Denmark. CG was composed by $75 \%$ glycerol, $10 \%$ animal fat, 1-2\% sulphur, $10 \%$ moisture, $5 \%$ ash and $<1 \%$ methanol and had a pH of $1.5[23]$.

\subsection{Osmotic pressure}

Osmotic pressure of the solutions was calculated based on the van't Hoff equation (equation 1) and osmolality measurements with an Osmomat 030-3P cryscopic osmometer (Gonotec GmbH, Germany).

$\prod=i M R T$

where $\prod$ is the osmotic pressure, $i$ the van't Hoff factor, $M$ the molar concentration of the solution, $\mathrm{R}$ the ideal gas constant $(0.08206 \mathrm{~L}$ atm/mol/K) and $\mathrm{T}$ the temperature $(\mathrm{K})$.

\subsection{Density of crude glycerol}

The density of crude glycerol was determined with the use of $5 \mathrm{~cm}^{3}$ Blaubrand $®$ specific gravity bottles (BRAND GMBH + CO KG, Germany). The pycnometers were pre-calibrated by the manufacturer at $20^{\circ} \mathrm{C}$ and with 3 decimal precision. 


\subsection{Forward osmosis membrane filtration}

Flat sheet membranes developed by Aquaporin A/S was used for the forward osmosis (FO) filtration [21,24]. FO was performed in acrylic custom made flow cells Sterlitech Acrylic CF042AFO (Sterlitech, USA). The filtration channels were $85 \mathrm{~mm}$ long, $39 \mathrm{~mm}$ wide and $23 \mathrm{~mm}$ deep on both sides, yielding a total active filtration area of $33.15 \mathrm{~cm}^{2}$. Filtration duration was set to $900 \mathrm{~min}$ and pumping was performed with LongerPump BT100-1L peristaltic pumps (Longer Precision Pump Co., Ltd, China) at a cross flow rate of either 50 or $173 \mathrm{ml} / \mathrm{min}$. Furthermore the active membrane layer was always placed towards the feed solution (FO mode) and counter-current mode was applied for the filtration of the liquids. The preparation procedure for the filtration was comprised by i) 30 min hydration of the membrane in Milli-q water, ii) loading the membrane in the acrylic chamber, iii) loading the feed and draw solutions, iv) remove any possible bubbles from the chamber and v) let the flux stabilise for $15 \mathrm{~min}$. The draw and feed solutions were kept homogeneous and at a temperature of $37^{\circ} \mathrm{C}$ by means of a warm water bath and magnetic stirring (Karl Hecht GmbH \& Co KG, Germany). The relevant water fluxes were calculated by measuring the weight difference of the feed solution during time (measuring every $5 \mathrm{~min}$ ). The weight was measured by a standard FCB 24K2 Kern balance (KERN \& SOHN GmbH, Germany). A graphical representation of the FO membrane filtration system is shown in Fig. 2.

\subsection{Process model for the economic evaluation}

The economic evaluation focused on the most promising feedstock, which was the crude glycerol based on the water fluxes obtained. Butanol was considered the target product which could be obtained through fermentation of crude glycerol to butanol by Clostridium pasteurianum. Typical fermentation yields of butanol from crude glycerol in a suspended growth system with no 
in-situ butanol extraction were considered $0.21-0.30 \mathrm{~g} / \mathrm{g}$ glycerol [5]. In the process model, fermentation of a medium supplemented with $2 \% \mathrm{w} / \mathrm{w}$ crude glycerol resulted in an effluent containing $0.46 \%$ butanol with water accounting for the $97.5 \%$ of the total effluent mass. The process of butanol recovery from the fermentation broth with and without water recovery was modeled using SuperPro Designer® V9.0 software.

The butanol recovery and purification model applied in this study was based on the simulation model for separation of butanol from aquatic solutions that was suggested by Luyben [25]. That method was based on the formation of the heterogeneous azeotrope in the butanol/water systems which, unlikely the homogeneous azeotropes, e.g. that of ethanol/water, forms two phases that can be separated. Therefore, butanol can be effectively separated by using a simple two-column distillation system.

Fig. 3 shows the process model used for recovery and purification of butanol. The effluent stream of the fermentor is directed towards a storage tank (V-104), which also serves as a buffer tank. From the storage tank the stream is being heated to $339 \mathrm{~K}$ (HX-105) allowing any methanol to evaporate and then it is directed to a first distillation column (C-104) where butanol with the associated water to the azeotrope composition leaves the column from the top. The bottom stream containing all other components than butanol is leaving the system as waste. The butanol stream is cooled down to $343 \mathrm{~K}(\mathrm{HX}-101)$ and enters a tank (decanter, V-103) where two liquid phases, aqueous and organic, naturally separate. The aqueous phase (stream S-130) is sent back to the distillation (C-104) while the organic phase (stream S-129) is sent to a second distillation column (C-103). In the second distillation, water is the limiting component for the azeotrope so pure butanol is obtained from the bottom of the column while the azeotrope (S-131) is sent back to mixing (MX-103) with the distillate of the first column. Operating conditions were as suggested by Luyben [25]. 
Six different plant sizes with a butanol production capacity ranging from 600 to 1300 tonnes per year were considered in the economic evaluation, with the foreseen capacity of DAKA ecoMotion plan in Denmark being at 810 tonnes per year. Simulations were done for 4 different water recoveries, $10 \%, 30 \%, 50 \%$ and $70 \%$. Water recovery was simulated through a component splitting unit procedure in Super Pro Designer, which allowed altering the $\%$ water content in the fermentation effluent stream thus miming an FO unit. Two costs categories were taken into consideration in the economic evaluation: utilities cost, that is the total cost of heating/cooling utilities (i.e., heat transfer agents) and power utilized in the process and facility-dependent cost, which accounts for additional costs related to the use of the facility typically calculated as the sum of the costs associated with equipment maintenance, depreciation of the fixed capital cost, and miscellaneous costs such as insurance, local (property) taxes and possibly other overhead-type of factory expenses. Default values in the SuperPro Designer software were used for the estimation of the costs.

\section{Results and discussion}

\subsection{Filtration experiments}

Firstly, the potential of the pre-treated and enzymatically hydrolysed wheat straw, as a draw solution was evaluated. PHWS was tested in the past for its butyric acid production potential and it had been found that a $10 \%$ diluted PHWS solution could support growth of Clostridium tyrobutyricum DSM 2637 without any preceding adaptation needed [12]. Moreover, around 10\% was the dilution of feedstock where the end-product inhibition would be negligible or very low (giving approximately $5 \mathrm{~g} / \mathrm{l}$ butyric acid). Therefore, 5 and 20\% diluted solutions of PHWS were tested as feed solutions as they were considered closer to the case where feedstock and end-product inhibition effects would be manageable by the microbial strain without any additional intervention 
(i.e. adaptation and/or in situ product removal). The osmotic pressure potential of different PHWS concentrations are summarised in Table 1. As expected, the higher the concentration of wheat straw the greater the osmotic pressure of the solution. Undiluted PHWS demonstrated 42.6 bar of osmotic pressure, whereas a 1.8 bar was measured for a 5\% PHWS solution.

Table 1. Osmolality of various pre-treated and enzymatically hydrolysed wheat straw solutions

\begin{tabular}{lll}
\hline PHWS & Osmol/kg & Pi(bar) \\
\hline $100 \%$ & $1.653 \pm 0.039$ & $42.6 \pm 1.015$ \\
$50 \%$ & $0.784 \pm 0.0056$ & $20.2 \pm 0.141$ \\
$20 \%$ & $0.301 \pm 0.02$ & $7.75 \pm 0.495$ \\
$5 \%$ & 0.068 & 1.8 \\
$0 \%$ (Milli-Q water) & $0.005 \pm 0.0006$ & $0.025 \pm 0.028$ \\
\hline
\end{tabular}

Three set ups were prepared as shown in Table 2. Milli-Q water was used as a reference feed solution for the water flux potential and a water flux $\left(J_{\mathrm{w}}\right)$ of $6.21 \mathrm{~L} / \mathrm{m}^{2} / \mathrm{h}$ was recorded for the first 30 min of filtration. A $13.5 \%$ drop in the water flux was measured for the filtration using a $5 \%$ PHWS solution in water as a feed and undiluted PHWS as a draw, when compared to the first set up. For the last set-up, a 20\% PHWS solution was used as a feed solution and undiluted PHWS as a draw solution, giving a $\mathrm{J}_{\mathrm{w}}$ of $1.33 \mathrm{~L} / \mathrm{m}^{2} / \mathrm{h}$.

Table 2. Water fluxes $\left(\mathrm{J}_{\mathrm{w}}\right)$ obtained with undiluted PHWS as draw solution

\begin{tabular}{llll}
\hline Feed solution & Draw solution & $\mathbf{J}_{\mathbf{w}}\left(\mathbf{l} / \mathbf{m}^{\mathbf{2}} / \mathbf{h}\right)$ & $\begin{array}{l}\text { Cross flow-rate } \\
(\mathbf{m l} / \mathbf{m i n})\end{array}$ \\
\hline Milli-Q & $100 \%$ PHWS & 6.21 & 50 \\
$5 \%$ PHWS & $100 \%$ PHWS & 5.37 & 50 \\
$20 \%$ PHWS & $100 \%$ PHWS & 1.33 & 50 \\
\hline
\end{tabular}

Following the wheat straw filtration, crude glycerol was also tested for its water recovery potential. The main problems associated to the crude glycerol fermentation for butanol production is the 
nature of the feedstock itself, which is quite inhibitory for microbial growth due to the high concentration of long fatty acids (coming from animal fat), methanol and ions but also butanol which severely inhibits microbial growth. Due to its toxic effects, a maximum $17 \mathrm{~g} / \mathrm{L}$ butanol concentration in fermentation broths is rarely achieved while typical butanol concentration is within the range of 2-13 g/L in most of the relevant literature studies at suspended growth reactors and without in-situ butanol removal [5]. Therefore, 1, 2 and 5\% diluted solutions of crude glycerol (containing 9.4, 18.7 and $46.8 \mathrm{~g}$ glycerol/1, respectively) were considered as realistic concentrations to be tested as feed solutions. Crude glycerol solutions with 1,2 and 5\% content in glycerol are expected to reach 2-2.8, 3.9-5.6 and 9.8-14 g butanol/L when fermented with Clostridium pasteurianum in batch, suspended growth systems based on the reported yields of $0.21-0.30 \mathrm{~g}$ butanol/g glycerol [5].

In regards to the FO application potential, the great advantage of crude glycerol as a feedstock is its high osmolality. As showed in Table 3, undiluted crude glycerol has an osmotic pressure of 468.5 bar, which is an approximately 10 -fold higher than that of a $1 \mathrm{M} \mathrm{NaCl}$ solution. Furthermore, even when diluted 20 -fold, crude glycerol solutions, still demonstrated 13.33 bar of osmolality. This can be considered quite high when compared to PHWS. On the downside, the undiluted crude glycerol is quite viscous and this can pose a problem for the filtration, since increased friction in the tubes and within the chamber can occur. According to Shaffer and colleagues low viscosity of draw solutions is, among others, an important characteristic [19]. The density of crude glycerol was measured to be $1.249 \mathrm{~g} / \mathrm{ml}$.

Initially, a set-up of $1 \%$ crude glycerol as a feed solution and undiluted crude glycerol as draw was tested. The cross-flow rate was set to $50 \mathrm{ml} / \mathrm{min}$. This set up gave a $\mathbf{J}_{\mathrm{w}}$ of $16.59 \mathrm{~L} / \mathrm{m}^{2} / \mathrm{h}$. However, the stability of the $\mathrm{J}_{\mathrm{w}}$ per function of time was poor, with standard deviation of \pm 5.53 $\mathrm{L} / \mathrm{m}^{2} / \mathrm{h}$. This could be attributed to the high viscosity of the liquid and the low cross-flow rate. In 
order to improve the testing, it was decided to increase the cross-flow rate to $173 \mathrm{ml} / \mathrm{min}$. Indeed, the second run showed higher $\mathrm{J}_{\mathrm{w}}$ consistency, yielding $10.5 \pm 1.43 \mathrm{~L} / \mathrm{m}^{2} / \mathrm{h}$. Following, a $2 \%$ crude glycerol solution was used as feed and undiluted crude glycerol as draw. This yielded a water flux of $8.99 \mathrm{~L} / \mathrm{m}^{2} / \mathrm{h}$, while a $5 \%$ crude glycerol solution used as feed yielded the also considerably high water flux of $8.39 \mathrm{l} / \mathrm{m}^{2} / \mathrm{h}$. The osmolality of the various solutions used during the abovementioned experimental set-ups and the corresponding water fluxes are shown in table 3.

Table 3. Osmolality of various solutions of crude glycerol and water fluxes obtained with undiluted crude glycerol as draw solution

\begin{tabular}{llll}
\hline $\begin{array}{l}\text { DAKA crude } \\
\text { glycerol (7/3/14) }\end{array}$ & Osmol/kg & $\begin{array}{l}\text { Osmotic pressure } \\
\mathbf{3 0 8 . 1 5} \mathbf{K}(\mathbf{b a r})\end{array}$ & $\begin{array}{l}\text { Water flux }^{\mathbf{a}} \\
\left(\mathbf{L} / \mathbf{m}^{\mathbf{2}} \mathbf{h}\right)\end{array}$ \\
& & & Runtime 30 $\mathbf{~ m i n}$ \\
\hline $100 \%$ & 18.29 & 468.5 & $8.39^{1}$ \\
$5 \%$ & 0.923 & 13.33 & 8.99 \\
$2 \%$ & 0.359 & 4.95 & 10.5 \\
$1 \%$ & 0.18871 & 2.54 & \\
\hline
\end{tabular}

${ }^{\mathrm{a}} \mathbf{J}_{\mathrm{w}}$ was considered $1 \mathrm{~h}$ after the initiation of the filtration

Pretreated wheat straw hydrolysate, PHWS, demonstrated water fluxes ranging from $1.33 \mathrm{~L} / \mathrm{m}^{2} / \mathrm{h}$ to $5.37 \mathrm{~L} / \mathrm{m}^{2} / \mathrm{h}$. On the other hand, crude glycerol solutions have reached higher water fluxes up to $10.5 \mathrm{~L} / \mathrm{m}^{2} / \mathrm{h}$. Similar $\mathrm{J}_{\mathrm{w}}$ have been demonstrated in the literature for cellulose triacetate membranes, ranging from $5.5 \mathrm{~L} / \mathrm{m}^{2} / \mathrm{h}$ [26] up to $11 \mathrm{~L} / \mathrm{m}^{2} / \mathrm{h}$ [27]. However, it should be highlighted that in the studies mentioned above, $\mathrm{NaCl}$ was used as draw solution and either Milli-Q or low concentration $\mathrm{NaCl}$ solutions as feed. Sodium chloride is characterized as a model draw solution because it can generate high osmolality and show low viscosity even at low concentrations [19]. Hence, the 
filtration was performed under ideal conditions, whereas in the case of PHWS and crude glycerol the conditions were far from optimal.

Based on the above, both feedstocks were considered promising cases for the application of FO as standalone step for re-use of water. Specifically, for wheat straw hydrolysate, there is still much potential for improvement by obtaining hydrolysates with higher osmotic pressures by altering the water added prior the pre-treatment and adjusting the conditions of the pre-treatment accordingly. As reported in previous studies, wheat straw hydrolysate was a rather challenging feedstock for sustaining microbial growth of Clostridium tyrobutyricum for production of butyric acid [12,28]. The wild microbial strain was not able to grow on higher dilutions of the hydrolysate than $10 \%$ and a series of time-consuming adaptation was needed in order to create a mutant able to grow on more concentrated hydrolysate [12]. Butyric acid as a product was also inhibitory itself for the microbial growth and the inhibition was overcome by applying in-situ acid removal by reverse electro enhanced dialysis $[15,28]$. Operating the biological process with diluted hydrolysate as influent and applying water recovery and recirculation by FO between the concentrated feedstock and the diluted effluent would be an alternative concept that could potentially result in comparable production costs eliminating thus the need of the lengthy microbial adaptation and in-situ products recovery. Such a comparison would be very interesting to be further investigated as it could be applicable to several other microbial processes subjected to feedstock and/or products inhibition.

Furthermore, it is important to underline that one of the major hurdles for large scale FO application is fresh water recovery and the subsequent regeneration of the salty solution. A hybrid FO-RO filtration have been proposed as an alternative, but this would make the overall process less energetically efficient than a simple RO separation [19]. On the contrary, a concentrated feedstock like crude glycerol can offer a realistic solution by eliminating the extra step of the draw solution regeneration. Instead, it can be directly utilized as fermentation feedstock after going through the 
FO system according to the scheme proposed in Section 1, Fig. 1. It is worthy to notice that preliminary experiments have shown that fermentation of $1.33 \%$ crude glycerol by $C$. pasteurianum exhibited negligible difference in the osmolality of the solution when compared to the diluted feedstock (C. pasteurianum was able to grow on 1-max. $2 \%$ of crude glycerol generated at DAKA). Thus, it is anticipated that the water fluxes with fermented effluent as feed solution will not significantly differ from those obtained with the diluted feedstock. Nevertheless, other factors can also affect the efficiency of filtration over time and should be taken into consideration in further experimentation. The most important in the present case is a) biofouling due to cell biomass accumulation, especially when higher concentrations of crude glycerol will be used in the fermentation broth and b) build-up of salts and solids on the active or the support layer of the membrane. Common and non-invasive methods for membrane fouling prevention and regeneration is rinsing with distilled water and back-flushing [16,29-33].

\subsection{Economic evaluation}

Based on the water fluxes obtained during the filtration tests, crude glycerol was considered the most promising feedstock to continue working with. Therefore, and as it was already mentioned in section 2.5, the economic evaluation of the downstream processing costs focused on a plant producing butanol from crude glycerol fermentation by C. pasteurianum. The downstream processing cost as a function of the plant size and at different water recoveries is shown in Fig. 4 . Fig. 5 shows the $\%$ decrease of downstream processing cost with water recirculation and Fig. 6 the utilities and facility costs.

One can see that a $10 \%$ water recovery actually resulted in almost equal $(10.38 \%)$ cost decrease. Similar results were yielded with the other set of simulations, which means that if a significant water recovery is achieved then a substantial cost reduction should be expected. As 
anticipated, the plant capacity is another important factor that affects the downstream processing cost; due to the economy of scale, a double size plant can reduce $37 \%$ the cost even without water recovery. Consequently, in case of water recovery the effect of the plant size remains the same and it can be combined with the effect of water recovery, e.g. a double plant size with $70 \%$ water recovery is accompanied by a $37 \%$ cost reduction due to the economy of scale plus the cost reduction due to the water recovery. The plant size also affects the relative magnitude of facility and utilities costs as shown in Fig. 6. Finally, the \% utilities cost contribution increases with the size of the plant while the $\%$ of facility cost contribution shows the opposite trend. According to the above figures and for the DAKA plant size with an annual throughput of $810000 \mathrm{~kg}$, the cost reduction was calculated for the different water re-use percentages compared to the process with no water reuse and are shown in Table 4. For the FO water recovery system, operational costs are expected to be significantly lower than the calculated cost reductions. FO energy consumptions have been reported by Mazlan et al. [34] and McGinnis et al. [35] between as low as 0.11 and $0.24 \mathrm{kWh} / \mathrm{m}^{3}$ respectively for FO desalination. Evidently, the absolute operational costs for the currently presented FO system will differ from the FO desalination system. Major dissimilarities are the absence of a FO draw recovery system, which actually lowers the cost of the present concept and higher viscosities to pump with, of which the effects on the costs are yet unknown. Nevertheless, the cited FO energy consumptions were assessed against main desalination techniques using 19.58$27.25 \mathrm{kWh} / \mathrm{m}^{3}, 14.45-21.35 \mathrm{kWh} / \mathrm{m}^{3}$ and $4-6 \mathrm{kWh} / \mathrm{m}^{3}$ for multistage flash, multi-effect desalination and seawater RO, respectively [36], indicating a low energy consumption for FO. Moreover, viscosity is only expected high in the undiluted draw stream, which has a daily flow of $6.43 \mathrm{~m}^{3}$ as opposed to $300 \mathrm{~m}^{3}$ feed flow, herewith only representing $2 \%$ of the total volume to be pumped. Based on those figures and on an energy rate of $0.08 \mathrm{USD} / \mathrm{kWh}$ an indicative OPEX cost for the FO 
unit is provided is Table 4. The percentage of this indicative OPEX FO cost in relation to the cost reduction is also given in Table 4.

Moreover, membrane CAPEX costs for the FO water recovery process have been assessed. The expected market introduction price for Aquaporin Inside ${ }^{\mathrm{TM}}$ flat sheet FO membranes accounts to $42 \mathrm{USD} / \mathrm{m}^{2}$. For the DAKA ecoMotion plant, an FO membrane area of $117,351,585$ and $819 \mathrm{~m}^{2}$ is expected to reach water recoveries of $10,30,50$ and $70 \%$ respectively (calculated for a butanol producing plant fermenting $2 \%$ crude glycerol and generating $300 \mathrm{~m}^{3} / \mathrm{d}$ of fermentation effluent). The respective cost for the abovementioned membrane areas is thus estimated to 4914,14742 , 24570 and $34398 \mathrm{USD}$, or $6.07 \cdot 10^{-3}, 0.018,0.030$ and $0.042 \mathrm{USD} / \mathrm{kg} \mathrm{MP}$, respectively. CAPEX costs other than membrane costs for the FO system are not yet fully analyzed; however, the membrane CAPEX is two orders of magnitude lower compared to the cost reduction presented in Table 4. This is a strong indication that the proposed concept would be economically viable resulting in significant cost reduction and economical gain. Still, the exact magnitude of the economic benefits of the proposed concept needs to be assessed with an extensive study including both OPEX and CAPEX cost calculations for the FO system after long term experiments are performed and several factors including fouling and cleaning/regeneration of membranes are evaluated.

From the present work, it may be concluded that there is a clear potential for FO membrane separations being applied as standalone technology for the re-use of water in bio-based production processes. A pre-condition for considering application of the proposed concept is that the feedstock has an osmotic pressure that allows for high water fluxes when the effluent of the fermentation process is used as the feed solution. This depends on the osmotic pressure of feedstock itself but also on the necessity for its dilution before being biologically processed due to physiological limitations, i.e. inhibition effects, as discussed already in the introduction, Section 1. In the sequel, 
other issues regarding the performance of the FO should be addressed like i) the long term response of the membrane in foulants, ii) the optimal operating parameters and iii) the possible approaches for the cleaning/regeneration of the membranes. It has been shown that during filtration various organic and inorganic substances can form a layer on the surface of the membranes and hence reduce its performance [37]. Furthermore, the optimal operational parameters for the current set-up should be investigated by testing the effect of cross-flow velocity and osmolality difference along the membrane. Interestingly, the first has been proposed as a solution for membrane fouling since high liquid flow might rinse the membranes from foulants [38].

Table 4. Cost reduction and indicative Forward Osmosis operating expenses (FO OPEX) for a plant with an annual throughput of $810000 \mathrm{~kg}$ as calculated based on [34,35]. Indicative \% FO OPEX cost is on the basis of cost reduction.

\begin{tabular}{llll}
\hline Water reuse in & Cost reduction, & $\begin{array}{l}\text { Indicative FO } \\
\text { OPEX USD/kg }\end{array}$ & Indicative \% FO \\
the process, $\%$ & USD/kg MP & MP & \\
& & $0.002-0.0004$ & $0.055-0.110$ \\
\hline 10 & 0.363 & $0.0006-0.0012$ & $0.061-0.122$ \\
50 & 0.980 & $0.0009-0.0020$ & $0.055-0.122$ \\
70 & 1.634 & $0.0013-0.0029$ & $0.056-0.124$ \\
\hline
\end{tabular}

\section{Conclusions}

A novel study of water recovery potential via forward osmosis separation technology has been performed, using two abundant biorefinery feedstocks. This approach can revolutionise and offer a sustainable solution to the problem of water recovery, draw solution regeneration and 
product up-concentration. Regarding the water recovery potential, crude glycerol has demonstrated water fluxes up to $10.5 \mathrm{~L} / \mathrm{m}^{2} / \mathrm{h}$. Moreover, the potential benefits from the water recovery have been supported by an economic evaluation. Namely, fermentation of crude glycerol to butanol with C. pasteurianum was subjected to economic analysis and revealed that a $50 \%$ water re-use had as an effect the reduction of butanol purification costs by almost $50 \%$. Indicative major FO operational and capital costs were very low compared to the potential economic benefits of the process due to water re-use. Conclusively, there is a clear potential for FO membrane separations being applied as standalone technology for the re-use of water in biorefineries especially with feedstocks characterised by high osmotic pressure.

\section{Acknowledgements}

The authors gratefully acknowledge financial support from the Innovation Fund Denmark (IBISS: Industrial Biomimetic Sensing and Separation) and the Technical University of Denmark. Supply of crude glycerol and information relevant to the techno economic analysis from DAKA ecoMotion is also greatly acknowledged.

\section{References}

[1] Intergovernmental Panel on Climate Change, Climate Change 2014: Synthesis Report, 2014.

[2] P. Baladincz, J. Hancsók, Fuel from waste animal fats, Chem. Eng. J. 282 (2015) 152-160.

[3] X. Yang, H.S. Choi, C. Park, S.W. Kim, Current states and prospects of organic waste utilization for biorefineries, Renew. Sustain. Energy Rev. 49 (2015) 335-349. 
[4] L.J. Jonsson, C. Martin, Pretreatment of lignocellulose: Formation of inhibitory by-products and strategies for minimizing their effects, Bioresour. Technol. 199 (2016) 103-112.

[5] E. Johnson, T. Sarchami, S. Kießlich, G. Munch, L. Rehmann, Consolidating biofuel platforms through the fermentative bioconversion of crude glycerol to butanol., World J. Microbiol. Biotechnol. 32 (2016) 103.

[6] M.G. Alvarez, A.M. Segarra, S. Contreras, J.E. Sueiras, F. Medina, F. Figueras, Enhanced use of renewable resources: Transesterification of glycerol catalyzed by hydrotalcite-like compounds, Chem. Eng. J. 161 (2010) 340-345.

[7] J.R.M. Almeida, L.C.L. Fávaro, B.F. Quirino, Biodiesel biorefinery: opportunities and challenges for microbial production of fuels and chemicals from glycerol waste, Biotechnol. Biofuels. 5 (2012) 48.

[8] A. Chatzifragkou, S. Papanikolaou, Effect of impurities in biodiesel-derived waste glycerol on the performance and feasibility of biotechnological processes, Appl. Microbiol. Biotechnol. 95 (2012) 13-27.

[9] F.W. Bai, W.A. Anderson, M. Moo-Young, Ethanol fermentation technologies from sugar and starch feedstocks, Biotechnol. Adv. 26 (2008) 89-105.

[10] D. Michel-Savin, R. Marchal, J.P. Vandecasteele, Butyrate Production in Continuous Culture of Clostridium tyrobutyricum - Effect of End-Product Inhibition, Appl. Microbiol. Biotechnol. 33 (1990) 127-131.

[11] J.K. Ko, Y. Um, Y.C. Park, J.H. Seo, K.H. Kim, Compounds inhibiting the bioconversion of hydrothermally pretreated lignocellulose, Appl. Microbiol. Biotechnol. 99 (2015) 42014212. 
[12] G.N. Baroi, I. Baumann, P. Westermann, H.N. Gavala, Butyric acid fermentation from pretreated and hydrolysed wheat straw by an adapted Clostridium tyrobutyricum strain, Microb. Biotechnol. 8 (2015) 874-882.

[13] R. Manosak, S. Limpattayanate, M. Hunsom, Sequential-refining of crude glycerol derived from waste used-oil methyl ester plant via a combined process of chemical and adsorption, Fuel Process. Technol. 92 (2011) 92-99.

[14] K.W. Staggs, D.R. Nielsen, Improving n-butanol production in batch and semi-continuous processes through integrated product recovery, Process Biochem. 50 (2015) 1487-1498.

[15] G.N. Baroi, I. V Skiadas, P. Westermann, H.N. Gavala, Effect of in situ acids removal on mixed glucose and xylose fermentation by Clostridium tyrobutyricum, AMB Express. 5 (2015).

[16] S. Zhao, L. Zou, C.Y. Tang, D. Mulcahy, Recent developments in forward osmosis: Opportunities and challenges, J. Memb. Sci. 396 (2012) 1-21.

[17] R. Valladares Linares, Z. Li, V. Yangali-Quintanilla, N. Ghaffour, G. Amy, T. Leiknes, J.S. Vrouwenvelder, Life cycle cost of a hybrid forward osmosis - low pressure reverse osmosis system for seawater desalination and wastewater recovery, Water Res. 88 (2016) 225-234.

[18] Y. Cai, X. 'Matthew' Hu, A critical review on draw solutes development for forward osmosis, Desalination. 391 (2016) 16-29.

[19] D.L. Shaffer, J.R. Werber, H. Jaramillo, S. Lin, M. Elimelech, Forward osmosis: Where are we now?, Desalination. 356 (2015) 271-284.

[20] L. Chekli, S. Phuntsho, J.E. Kim, J. Kim, J.Y. Choi, J.-S. Choi, S. Kim, J.H. Kim, S. Hong, J. 
Sohn, H.K. Shon, A comprehensive review of hybrid forward osmosis systems: Performance, applications and future prospects, J. Memb. Sci. 497 (2016) 430-449.

[21] C. Tang, Z. Wang, I. Petrinić, A.G. Fane, C. Hélix-Nielsen, Biomimetic aquaporin membranes coming of age, Desalination. 368 (2015) 89-105.

[22] J. Habel, M. Hansen, S. Kynde, N. Larsen, S.R. Midtgaard, G.V. Jensen, J. Bomholt, A. Ogbonna, K. Almdal, A. Schulz, C. Helix-Nielsen, Aquaporin-Based Biomimetic Polymeric Membranes: Approaches and Challenges, Membranes (Basel). 5 (2015) 307-351.

[23] C. Varrone, T.M.B. Heggeset, S.B. Le, T. Haugen, S. Markussen, I. V Skiadas, H.N. Gavala, Comparison of Different Strategies for Selection/Adaptation of Mixed Microbial Cultures Able to Ferment Crude Glycerol Derived from Second-Generation Biodiesel, Biomed Res. Int. (2015). doi:10.1155/2015/932934.

[24] Y. Zhao, C. Qiu, X. Li, A. Vararattanavech, W. Shen, J. Torres, C. Hélix-Nielsen, R. Wang, X. Hu, A.G. Fane, C.Y. Tang, Synthesis of robust and high-performance aquaporin-based biomimetic membranes by interfacial polymerization-membrane preparation and RO performance characterization, J. Memb. Sci. 423-424 (2012) 422-428.

[25] W.L. Luyben, Control of the Heterogeneous Azeotropic n-Butanol/Water Distillation System, Energy \& Fuels. 22 (2008) 4249-4258.

[26] A. D’Haese, P. Le-Clech, S. Van Nevel, K. Verbeken, E.R. Cornelissen, S.J. Khan, A.R.D. Verliefde, Trace organic solutes in closed-loop forward osmosis applications: Influence of membrane fouling and modeling of solute build-up, Water Res. 47 (2013) 5232-5244.

[27] A.A. Alturki, J.A. McDonald, S.J. Khan, W.E. Price, L.D. Nghiem, M. Elimelech, Removal of trace organic contaminants by the forward osmosis process, Sep. Purif. Technol. 103 
(2013) 258-266.

[28] G.N. Baroi, I. V Skiadas, P. Westermann, H.N. Gavala, Continuous Fermentation of Wheat Straw Hydrolysate by Clostridium tyrobutyricum with In-Situ Acids Removal, Waste and Biomass Valorization. 6 (2015) 317-326.

[29] S.K. Nataraj, S. Sridhar, I.N. Shaikha, D.S. Reddy, T.M. Aminabhavi, Membrane-based microfiltration/electrodialysis hybrid process for the treatment of paper industry wastewater, Sep. Purif. Technol. 57 (2007) 185-192.

[30] S.K. Nataraj, K.M. Hosamani, T.M. Aminabhavi, Distillery wastewater treatment by the membrane-based nanofiltration and reverse osmosis processes, Water Res. 40 (2006) 2349_ 2356.

[31] S.K. Nataraj, K.M. Hosamani, T.M. Aminabhavi, Nanofiltration and reverse osmosis thin film composite membrane module for the removal of dye and salts from the simulated mixtures, Desalination. 249 (2009) 12-17.

[32] R.S. Harisha, K.M.Hosamani, R.S. Keri, S.K. Nataraj, T.M. Aminabhavi, Arsenic removal from drinking water using thin film composite nanofiltration membrane, DESALINATION. $252(2010) 75-80$.

[33] S. Zhao, L. Zou, Relating solution physicochemical properties to internal concentration polarization in forward osmosis, J. Memb. Sci. 379 (2011) 459-467.

[34] N.M. Mazlan, D. Peshev, A.G. Livingston, Energy consumption for desalination - A comparison of forward osmosis with reverse osmosis, and the potential for perfect membranes, Desalination. 377 (2016) 138-151. 
[35] R.L. McGinnis, M. Elimelech, Energy requirements of ammonia-carbon dioxide forward osmosis desalination, Desalination. 207 (2007) 370-382.

[36] A. Al-Karaghouli, L.L. Kazmerski, Energy consumption and water production cost of conventional and renewable-energy-powered desalination processes, Renew. Sustain. Energy Rev. 24 (2013) 343-356.

[37] S. Lee, C. Boo, M. Elimelech, S. Hong, Comparison of fouling behavior in forward osmosis (FO) and reverse osmosis (RO), J. Memb. Sci. 365 (2010) 34-39.

[38] Y. Kim, M. Elimelech, H.K. Shon, S. Hong, Combined organic and colloidal fouling in forward osmosis: Fouling reversibility and the role of applied pressure, J. Memb. Sci. 460 (2014) 206-212. 


\section{FIGURE LEGENDS}

Fig. 1. Schematic diagram of the proposed process on FO application for water recovery:

Fermented broth and concentrated substrate are used as feed and draw solution for FO application, respectively. Consecutively the diluted feedstock is fermented and the concentrated product is subjected to downstream processing.

Fig. 2. Graphical representation of the off-line Forward Osmosis filtration system. The water transfer is demonstrated by the dashed lines.

Fig. 3. Process model for recovery and purification of butanol.

Fig. 4. The downstream processing cost in \$ per kg main product, MP (butanol), as a function of the plant size in kg butanol per year and at different water recoveries. The dashed vertical line demonstrates the current Daka ecoMotion crude glycerol annual production.

Fig. 5. Percent decrease of the downstream processing cost for butanol recovery.

Fig. 6. Contribution of utilities and facilities to the downstream processing cost. 


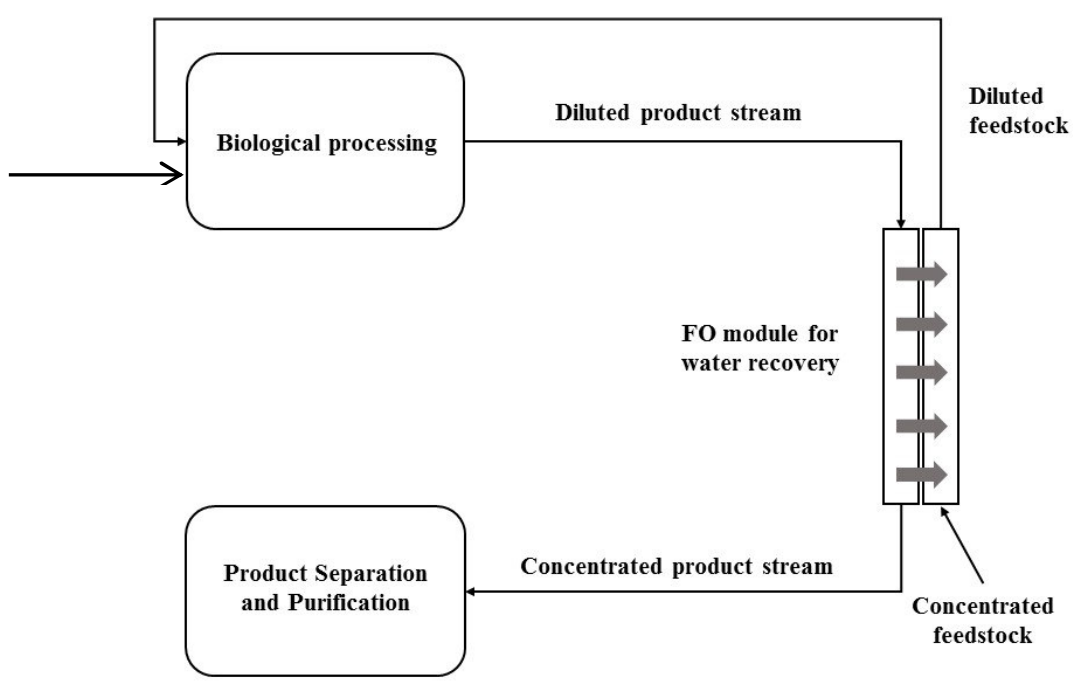

Fig. 1 


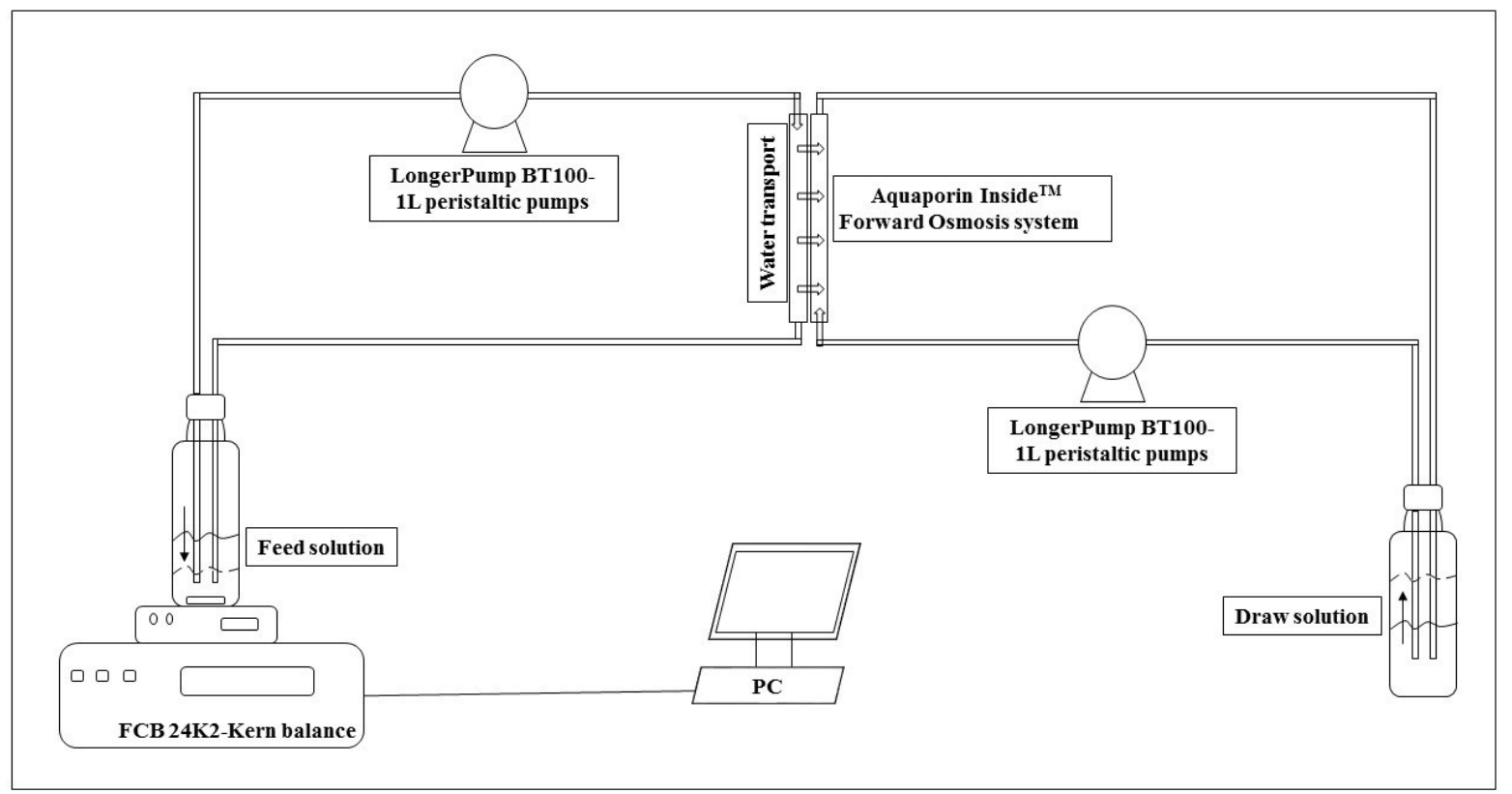

Fig. 2 


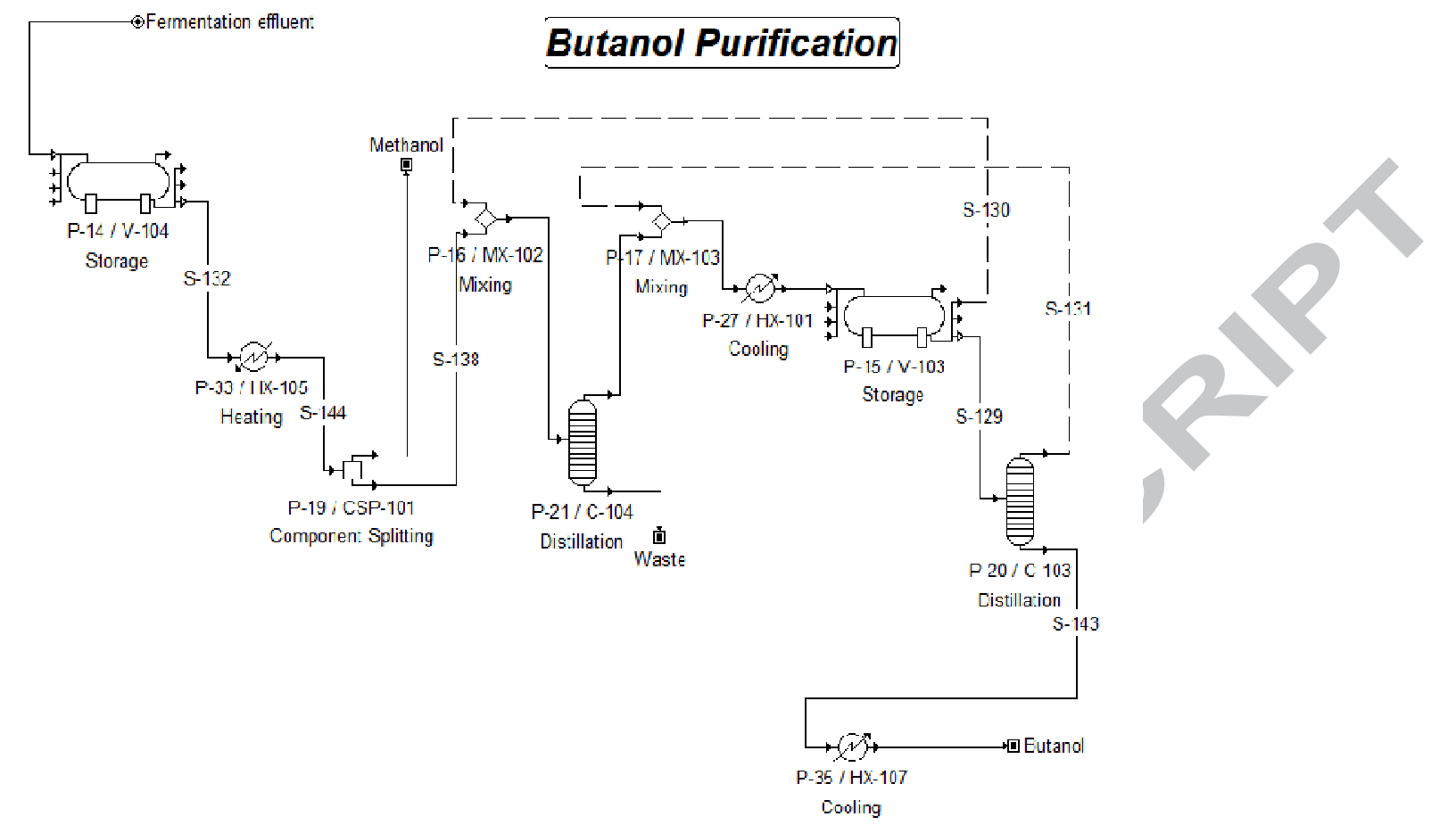

Fig. 3 


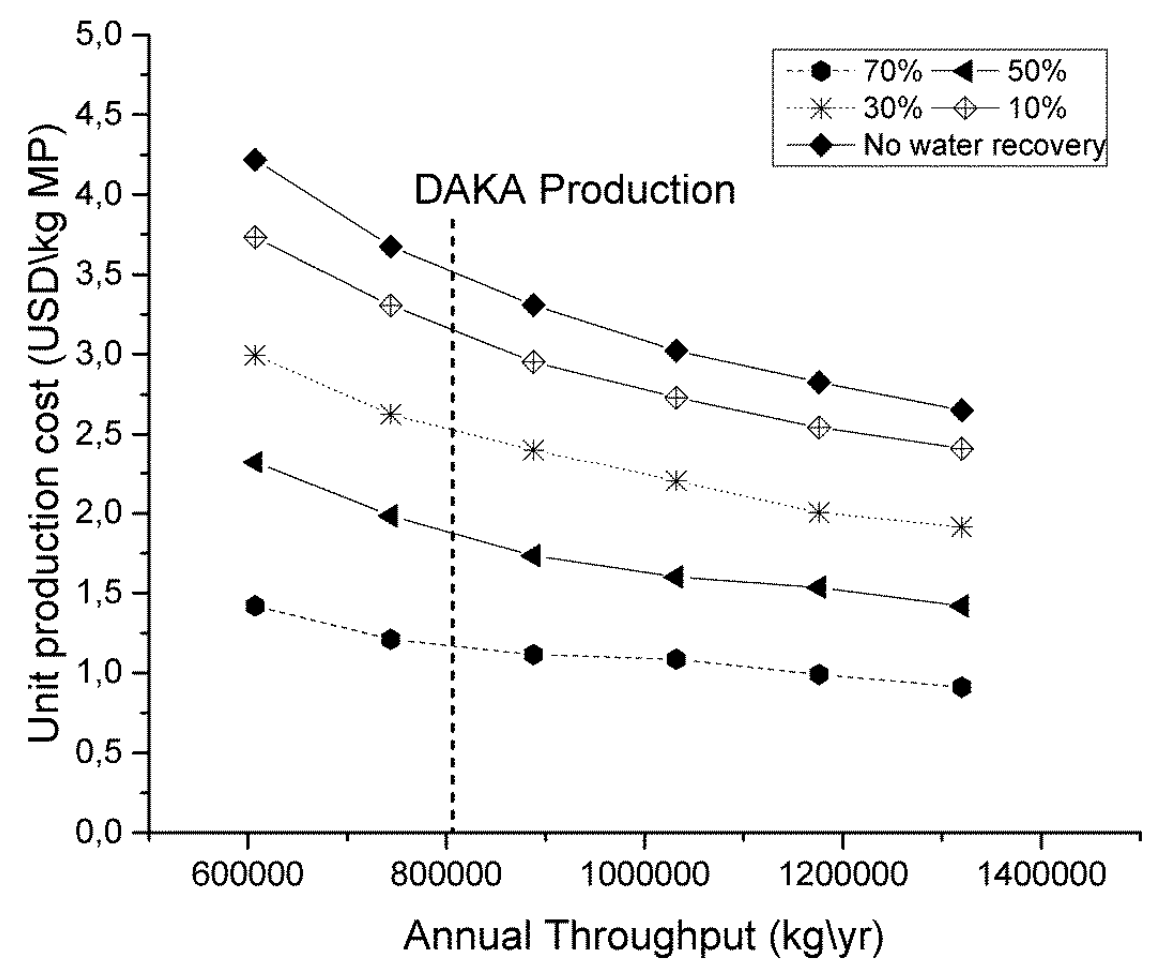

Fig. 4 


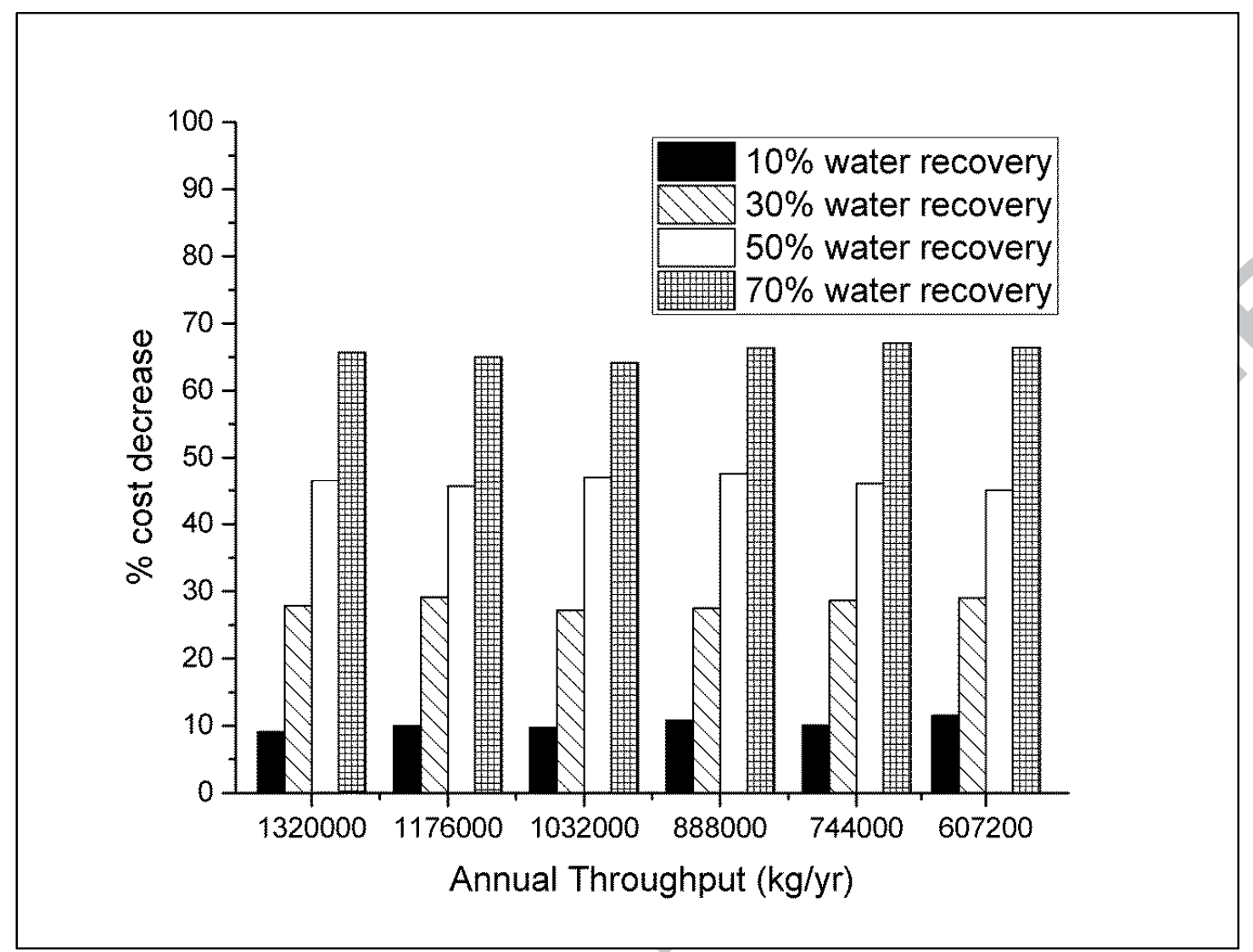

Fig. 5 


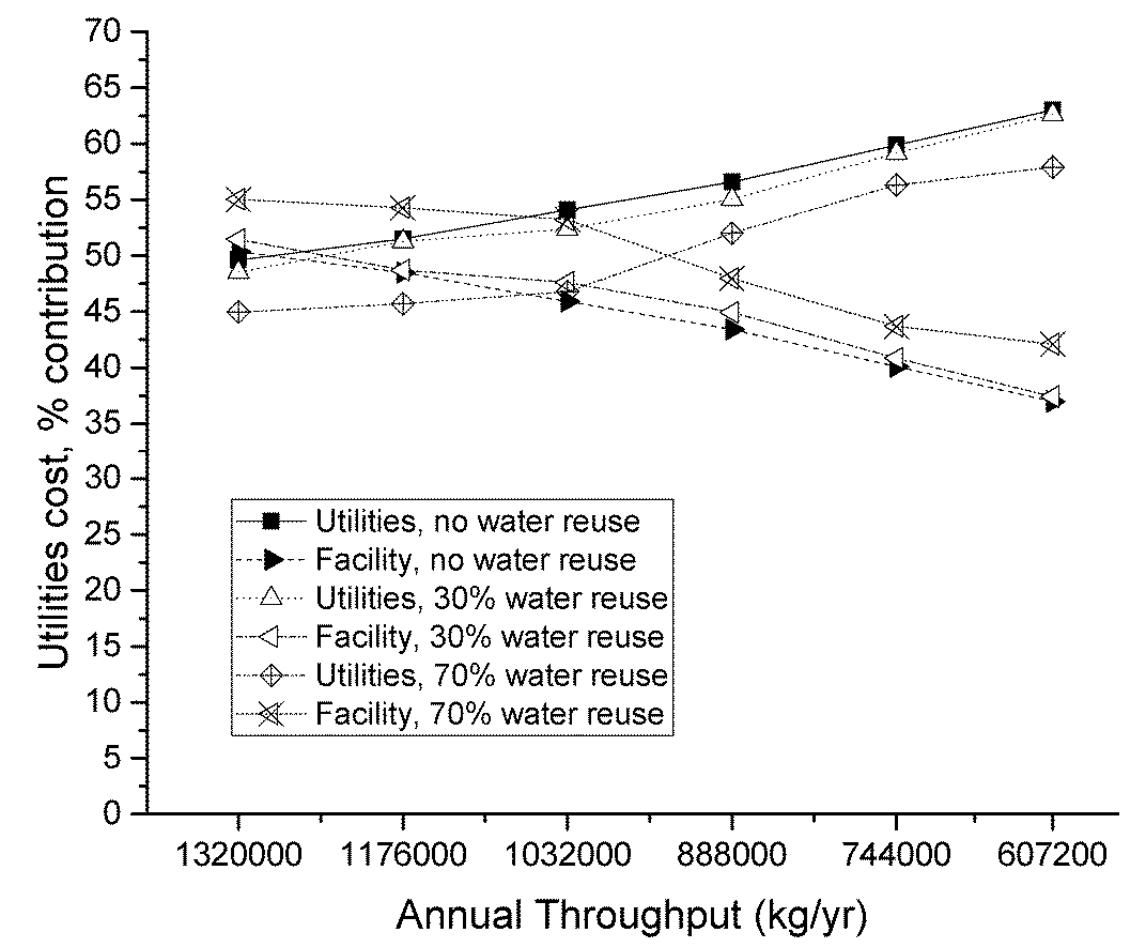

Fig. 6 


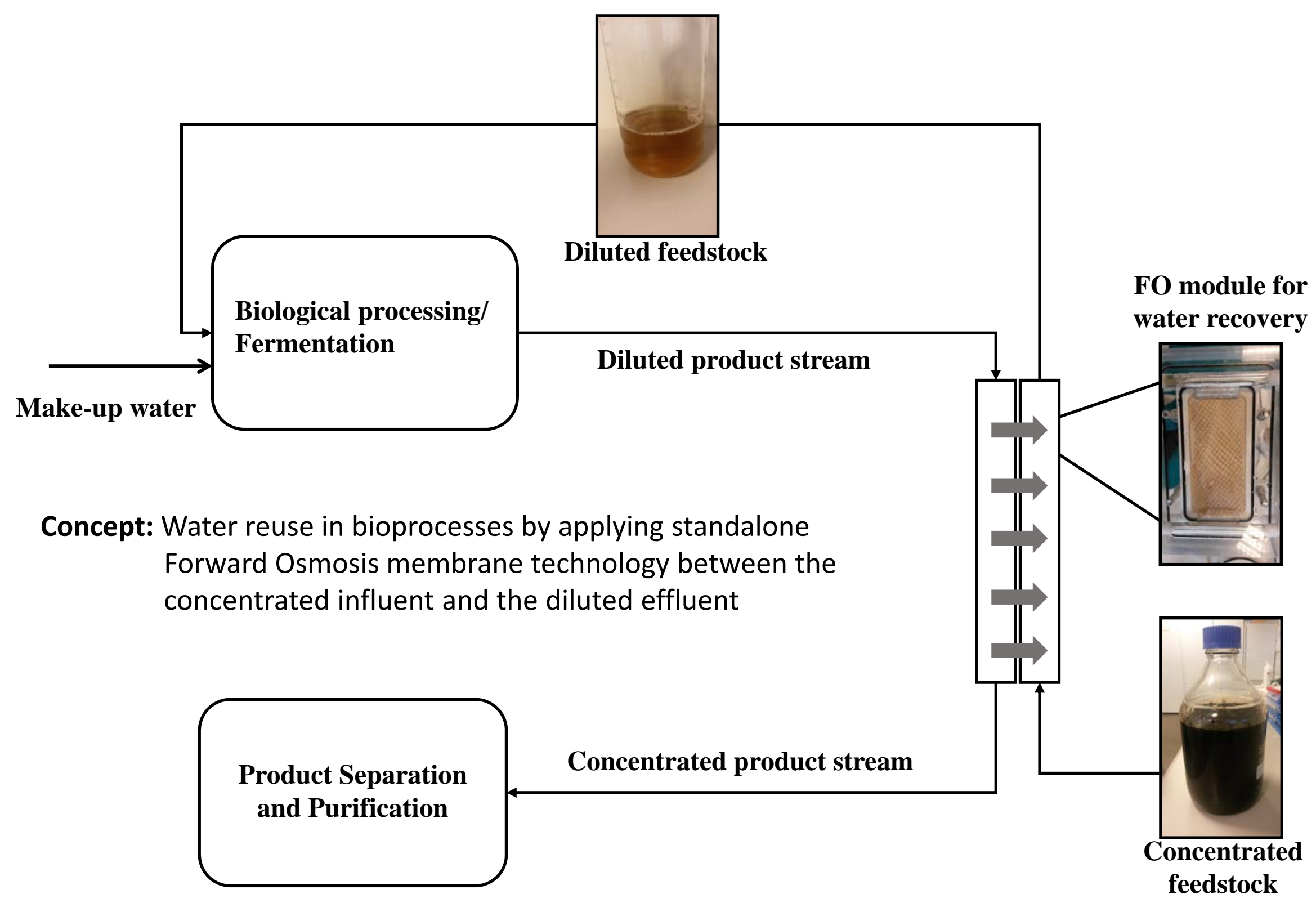




\section{Highlights}

- Standalone forward osmosis, FO, can be applied for water reuse in bioprocesses

- The concept is promising for wheat straw hydrolysate and glycerol as feedstocks

- $50 \%$ water recirculation resulted in $50 \%$ reduction of butanol purification cost

- Indicative FO OPEX are negligible compared to cost reduction due to water reuse 